\title{
MORFOLOGIA E DINÂMICA DA ORLA COSTEIRA DO MARAÚ, ILHA DE MOSQUEIRO, BELÉM, PARÁ
}

Resumo: A orla do Maraú, ilha de Mosqueiro, Pará, adquire notoriedade em função da maior frequência de fenômenos dinâmicos, nos últimos anos. A erosão é o principal fator, mas não ocorre de maneira uniforme, nem com a mesma intensidade ao longo da orla. Este trabalho objetiva a compartimentação morfológica e a análise de indicadores de dinâmica costeira da orla estudada visando à classificação do grau de erosão e/ou acumulação. A metodologia baseia-se na seleção de indicadores, análise quantitativa e mapeamento. Os resultados permitem estabelecer quatro setores: setor 1 (baixa erosão), setor 2 (média erosão), setor 3 (baixa acumulação) e setor 4 (estabilidade). A erosão predomina em setores expostos à baía de Marajó. A baixa acumulação e a estabilidade ocorrem nos setores protegidos.

Palavras-chave: Indicadores. Erosão. Orla. Ocupação.

\section{MORPHOLOGY AND DYNAMIC OF MARAÚ SHORELINE, MOSQUEIRO ISLAND, BELÉM, PARÁ}

Abstract: The waterfront of Maraú, Mosqueiro island, Pará, acquires visibility because of the occurrence of dynamic phenomena, in the last few years. The erosion is the main factor, but it does not occur in an even way, nor with the same intensity. This paper aims the morphologic partitioning and the analysis of the indicators of the researched coastal dynamics sorting out levels of erosion and/or accumulation. The methodology is based on indicators selection, quantitative analysis and mapping. The results show a shore division in four sectors: sector 1 (low erosion), sector 2 (average erosion), sector 3 (low accumulation) and sector 4 (stability). The erosion is predominant at sections exposed to Marajó bay. The low accumulation and stability occur in protected sectors of the shore.

Keywords: Indicators. Erosion. Coast. Occupation.

\section{MORFOLOGÍA Y DINÁMICA DE LA FRANJA COSTERA DEL MARAÚ, ISLA DE MOSQUEIRO, BELÉM, PARÁ}

Resumen: La costa del Maraú, isla de Mosqueiro, Pará, ha experimentado en los últimos años notoriedad por los procesos acelerados de fenómenos dinámicos. La erosión es el principal factor, pero no ocurre de manera uniforme, ni con la misma intensidad al largo de la franja costera. Este artículo se orienta para la

\footnotetext{
${ }^{1}$ Escola Estadual de Ensino Médio e Técnico Maria de Nazaré Guimarães Macedo, Escola Estadual de Ensino Fundamental e Médio Gonçalo Ferreira e Escola Estadual de Ensino Fundamental e Médio Raimunda Sena da Silva, Curuçá-PA, Brasil, caroline2010ribeiro@gmail.com, https://orcid.org/00000002-5288-9249

2 Universidade Federal do Pará, Faculdade de Geografia e Cartografia, Belém-PA, Brasil, carmena@ufpa.br, https://orcid.org/0000-0001-8879-5191

${ }^{3}$ Universidade Federal do Pará, Faculdade de Geografia e Cartografia, Belém-PA, Brasil, rhuanrodrigosilva@gmail.com, https://orcid.org/0000-0003-4506-6049
} 
compartimentación morfológica y el análisis de indicadores de la dinámica costera visando la clasificación del grado de erosión y/o acumulación. La metodología ha comprendido la selección de los indicadores, análisis cuantitativo y mapeo. El litoral del Maraú se constituye en cuatro sectores: sector 1 (baja actividad de la erosión), sector 2 (media actividad de la erosión), sector 3 (acumulación) y sector 4 (estabilidad). La erosión es predominante en los sectores frontales a la bahía de Marajó. La baja acumulación y la estabilidad ocurren en los sectores más protegidos.

Palabras clave: Indicadores. Erosión. Costa. Ocupación.

\section{Introdução}

A ilha de Mosqueiro localiza-se na parte norte do município de Belém do Pará, litoral norte do país. Pela localização geográfica, insere-se nas áreas estuarinas do Golfão Amazônico, sob influência direta das baías de Marajó, Santo Antônio e do Sol, além do furo das Marinhas. É uma área sujeita a marés com amplitudes de até 3,9 m durante as sizígias de março, abril e setembro (BRASIL, 2018). As ondas podem atingir alturas de 1,0 a $1,5 \mathrm{~m}$ geradas por ventos mais fortes provenientes do quadrante norte-nordeste, durante o período de julho a novembro. Os índices pluviométricos variam ao longo do ano, porém, distingue-se um período chuvoso entre os meses de janeiro a maio (PINHEIRO, 1987).

A orla do Maraú, área de estudo deste trabalho, situa-se na parte noroeste da ilha de Mosqueiro (Figura 1). Suas praias, que se distribuem na margem da baía de Marajó, são consideradas como atrativos turísticos e como espaços alternativos de lazer para boa parte da população belenense, principalmente no período de férias escolares, nos finais de semana e nos feriados, reforçando sua importância econômica e social para a Região Metropolitana de Belém. 
Figura 1 - Localização da área de estudo no noroeste da ilha de Mosqueiro, Belém, Pará.

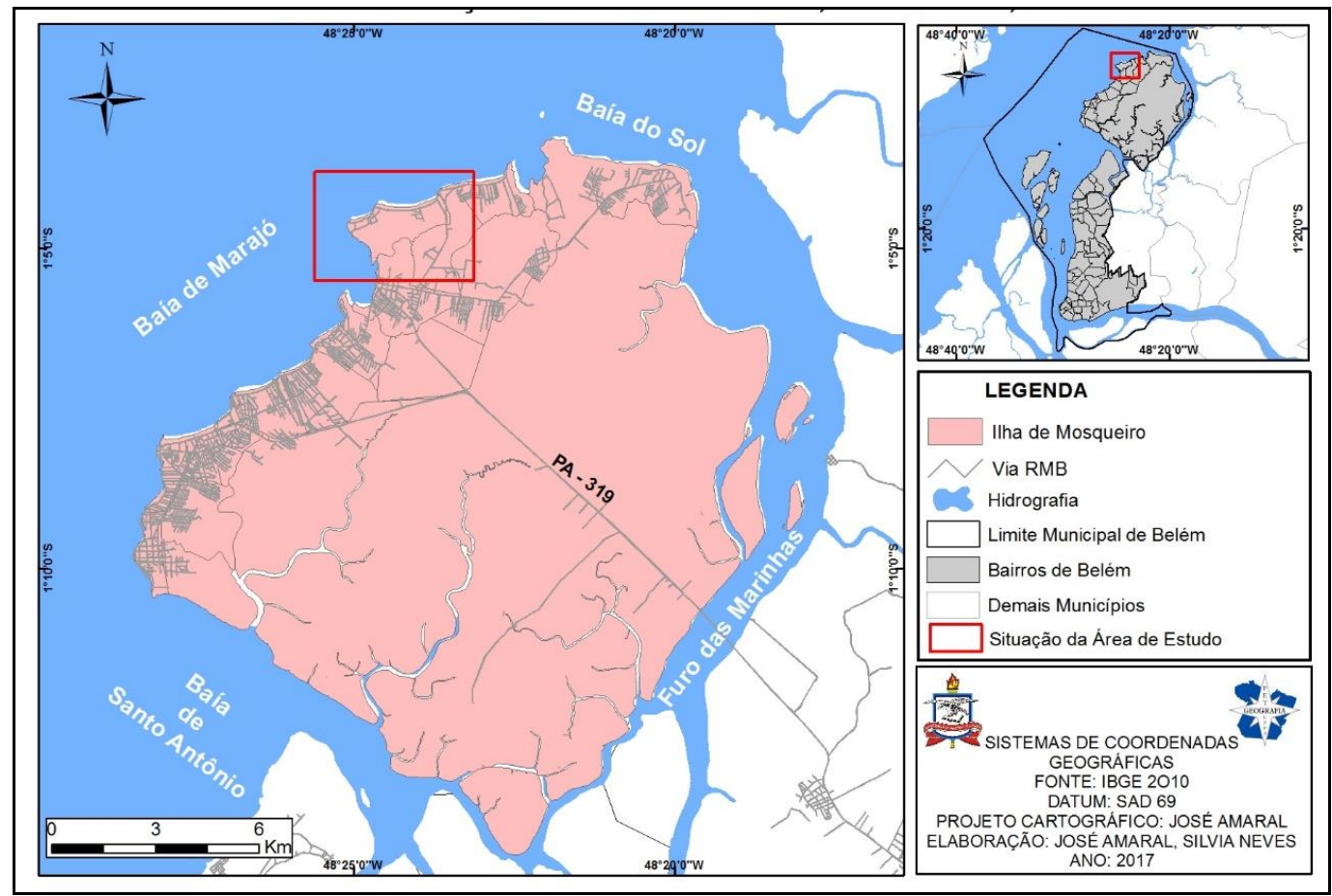

Fonte: Neves (2017).

A orla do Maraú pertence ao contexto urbano de Mosqueiro, com oferta de serviços, infraestrutura para circulação viária e predomínio do uso residencial e comercial. Nos últimos anos, o Maraú adquiriu notoriedade em função da ocorrência de fenômenos erosivos que atingem praias, falésias, construções e vias de acesso, causando preocupação à população local e aos gestores municipais. Porém, a erosão não se dá de maneira uniforme, nem com a mesma intensidade ao longo da orla. Há setores em que ela atinge diversos tipos de construção e de equipamentos urbanos, destrói vias de modo a dificultar ou interromper a circulação. Em outros, não atinge áreas ocupadas, manifesta-se sem alterar significativamente o meio físico ou cede lugar a fenômenos de acumulação.

Nas áreas mais ocupadas da mesma, os bares, pousadas e segundas residências estendem-se desde a borda superior das falésias até a praia, tornandose vulneráveis à ação das marés altas, ondas e chuvas. Isso obriga os proprietários, comerciantes e moradores a investirem em obras de contenção de erosão, aterros e na manutenção periódica de pilares de sustentação, de alicerces e calçadas. São muitas as tentativas por parte da população, juntamente com a ação de órgãos da prefeitura, em conter o processo erosivo em determinados setores. Porém, há 
intervenções sem planejamento adequado, tais como o empilhamento de sacos de areia, aterros e construção de muros de arrimo, alguns dos quais de modo improvisado e totalmente vedados, impossibilitando ou dificultando o equilíbrio do freático com os níveis das marés.

Entende-se que o estudo da erosão costeira é importante não apenas por ser um fenômeno de ordem física, mas também porque os processos erosivos têm frequentemente efeitos de cunho social e econômico, que ampliam o interesse dos autores por este trabalho. Considerando-se que a área de estudo é ocupada há muitas décadas e que os fenômenos de erosão ocorrem de maneira desigual ou irregular ao longo da área considerada, é necessário elaborar uma avaliação que subsidie o diagnóstico da situação local. Assim, este artigo tem como objetivo a compartimentação morfológica e a análise de indicadores de dinâmica costeira da orla do Maraú, tendo em vista a classificação da mesma quanto ao grau de erosão e/ou acumulação. O presente trabalho representa uma contribuição, no âmbito dos estudos geomorfológicos, para a geração de subsídios que possam munir os administradores públicos de elementos para a elaboração de políticas de ordenamento e planejamento da ocupação.

Os procedimentos metodológicos foram divididos em três etapas. A primeira constituiu-se de revisão e atualização bibliográfica acerca dos conceitos de zona costeira, orla costeira e sua delimitação, processos costeiros, indicadores físicos, biológicos e socioeconômicos de dinâmica costeira. Na segunda etapa, foram realizados três trabalhos de campo (maio e dezembro de 2016 e dezembro de 2017) para levantamento dos indicadores de dinâmica costeira, coleta de dados morfométricos e morfográficos, além de registros fotográficos, dados de elevação e de coordenadas com GPS, leituras de azimutes e ângulos verticais.

A terceira etapa foi cumprida em laboratório para interpretação da Imagem do Google Earth 2016 através do Programa Google Earth Pro, tratamento das informações de campo, confecção de mapas temáticos e tabelas, análise e interpretação dos resultados. Nesta fase da pesquisa, foi delimitado o polígono referente à orla do Maraú com base na compartimentação morfológica, associada aos critérios morfodinâmicos estabelecidos por Muehe (2001) para a orla costeira. A distribuição espacial dos indicadores permitiu a divisão da mesma em diferentes setores e a classificação destes de acordo com o grau de manifestação do fenômeno dinâmico (erosão ou acumulação, baixa, média ou alta, e estabilidade). 
Os indicadores adotados para a análise foram os seguintes: largura do arco praial, posição da linha de maré alta, largura da pós-praia e do estirâncio, presença/ausência de sistema barra-calha, granulometria de areia praial, presença/ausência de terracetes, falésias, promontórios, plataformas de abrasão e bancos de cascalho e porcentagem de ocorrência ao longo da orla, altura de falésias e promontórios, tipo de vegetação, condição erodida/soterrada e porcentagem de recobrimento da orla, construções destruídas/soterradas e porcentagem de ocorrência ao longo da mesma e, por fim, presença/ausência de tipos de feições erosivas/acrecionais.

A análise dos indicadores baseou-se em critérios espaciais e quantitativos, em que se destacaram a distribuição ou localização desses indicadores ao longo da orla, a definição de parâmetros extraídos dos dados morfométricos obtidos em campo e a atribuição de valores ou pesos, tendo em vista a classificação do grau de erosão ou de sedimentação em baixo (peso 1), médio (peso 2) e alto (peso 3). A metodologia adotada, neste trabalho, conduziu a uma análise de magnitude, frequência e intensidade dos fenômenos em curso na área estudada.

\section{Desenvolvimento}

Critérios de delimitação da orla costeira

O conceito de orla costeira e como delimitá-la formam a base teórica deste trabalho. Entretanto, é preciso inicialmente distinguir entre zona e orla costeira. Segundo Christofoletti (1980), a zona costeira é uma unidade formada por um conjunto de formas componentes da paisagem, que se estabelecem na área de contato entre o mar e o continente, com atuação de componentes marinhos, continentais e atmosféricos.

Gruber et al. (2003) definiram zona costeira como a área de interface entre o ar, mar e a terra. Trata-se de uma zona que vai desde os limites internos do continente, que sofrem interferência dos processos marinhos, tais como, as marés, até os limites externos dos ambientes marinhos, que são influenciados por processos terrestres, como as vazões fluviais. É nessa área que se formam os estuários, deltas, planícies de maré, pântanos salinos, ilhas barreiras, lagunas, praias e outras formas de relevo.

É possível delimitar, dentro da zona costeira, a orla. Logo, ela é parte da zona costeira. Muehe (2001) define-a como uma estreita faixa de contato terra-mar fragilizada diante dos processos costeiros, tais como a erosão. A erosão é um 
fenômeno natural, muitas vezes potencializada pela ação antrópica, principalmente diante das formas de uso e ocupação. Assim o seu conceito está ligado à proteção dessas áreas.

No sentido do planejamento e gestão das zonas costeiras, o Projeto Orla, desenvolvido pelo Ministério do Meio Ambiente (BRASIL, 2004), define a orla como parte integrante da zona costeira. Segundo este documento, a mesma representa uma faixa de largura variável, dentro da costa, cujos limites são estabelecidos da seguinte maneira: limite externo marcado pela isóbata de $10 \mathrm{~m}$ e limite interno definido pelo tipo de ocupação e pela fisiografia da costa. É uma unidade geográfica que possui interesses ecológicos e econômicos, por isso requer cuidados quanto à sua conservação. Assim, a orla marítima ou costeira ocupa uma parte específica da zona costeira, ou seja, é o espaço de contato imediato terra/mar e de interface de processos terrestres e marinhos, entendida como a borda marítima, estuarina ou lagunar da zona costeira, cuja escala cartográfica de representação adequada é de 1: 5.000, no máximo (BRASIL, 2004).

Para a definição dos seus limites internos, são consideradas as características morfológicas, topográficas, hidrológicas e ocupacionais. Nas áreas ocupadas pelo uso urbano com presença de falésias de rochas sedimentares, o limite interno da orla deve chegar a $50 \mathrm{~m}$, medidos a partir da borda superior das falésias em direção ao interior do continente ou da área emersa. Ou então, deve se estender até $200 \mathrm{~m}$ em áreas de falésias sedimentares não urbanizadas. No caso de falésias esculpidas em rochas cristalinas, a orla deve se estender a até $1 \mathrm{~m}$ acima do limite máximo alcançado pelas ondas mais altas. Para as costas baixas com presença de planícies alagáveis, o limite interno da mesma deve chegar a $1 \mathrm{~m}$ acima do nível da maré de sizígia. Se houver praias e dunas urbanizadas, a demarcação da orla deve se estender a até $50 \mathrm{~m}$, iniciando-se esta medida no limite superior da pós-praia ou no reverso da duna. No caso de praias e dunas não urbanizadas, de ocupação não consolidada ou rural, este limite pode se estender a até $200 \mathrm{~m}$. Os limites definidos para a orla e, consequentemente, para a largura da faixa de proteção podem ser modificados desde que os estudos sobre dinâmica costeira comprovem uma tendência erosiva que venha ultrapassar a demarcação estabelecida (MUEHE, 2001). 
Compartimentação morfológica do noroeste da ilha de Mosqueiro e delimitação da orla do Maraú.

De acordo com a escala de trabalho e a divisão taxonômica do relevo (ROSS, 1992), são identificadas, no noroeste da ilha de Mosqueiro, unidades de $4 .^{\circ}$ e 5. o táxons (Quadro 1). Essas unidades resultam de processos geomorfológicos atuantes entre o Terciário e o Quaternário, relacionados à neotectônica, às flutuações relativas do nível do mar, à hidrodinâmica atual (marés e ondas) e ao regime pluviométrico. Desse modo, a área de estudo apresenta uma variedade de feições morfológicas.

Quadro 1 - Divisão do relevo do noroeste da ilha de Mosqueiro em unidades de $4 . .^{\circ} \mathrm{e}$ 5.ำ táxons.

\begin{tabular}{|l|l|}
\hline UNIDADES DE 4. ${ }^{\circ}$ TÁXON & UNIDADES DE 5. ${ }^{\circ}$ TÁXON \\
\hline Baixo platô & $\begin{array}{l}\text { Falésia } \\
\text { Promontório } \\
\text { Plataforma de abrasão }\end{array}$ \\
\hline Praia de enseada & $\begin{array}{l}\text { Superfície de pós-praia } \\
\text { (supramaré) } \\
\text { Superfície de estirâncio (intermaré) } \\
\text { Banco de cascalho }\end{array}$ \\
\hline Restinga & $\begin{array}{l}\text { Superfície de pós-praia } \\
\text { (supramaré) } \\
\text { Superfície de estirâncio (intermaré) }\end{array}$ \\
\hline Planície aluvial & \\
\hline
\end{tabular}

Fonte: NEVES (2017).

$\mathrm{Na}$ ilha de Mosqueiro, particularmente no seu noroeste, a geometria da linha de costa é fortemente condicionada por sistemas de falhas geológicas, que atribuem à mesma um caráter irregular, recortado e anguloso, com a presença de falésias ativas, esculpidas em sedimentos do Grupo Barreiras/Pós-Barreiras (arenitos, argilitos, siltitos, conglomerados), contornadas por praias de enseada, limitadas em suas extremidades por promontórios (IGREJA et al., 1990; ROSSETTI, 2001). Por outro lado, a planície aluvial e as praias desenvolvem-se em setores deprimidos pela ação da neotectônica e, portanto, sujeitos à inundação por maré e aos processos deposicionais recentes do Holoceno (EL-ROBRINI, 2001; VIANA, 2013). As características morfológicas da orla do Maraú apresentam particularidades que dependem das variáveis do meio físico, relacionadas ao contexto estuarino no qual se insere. Tais variáveis influenciam nos processos desiguais de erosão e sedimentação que se distribuem ao longo da orla. 
A distribuição espacial das formas de relevo no noroeste da ilha de Mosqueiro, associada aos critérios definidos por Muehe (2001) para os limites da orla costeira, serviu de base para a delimitação desta no Maraú. Entretanto, a ausência de dados batimétricos e topográficos em escala de detalhe causou certa dificuldade para a demarcação. Assim, foram selecionados fatores alternativos, possíveis de serem reconhecidos em imagens de satélite e em trabalhos de campo. O limite externo foi fixado com base na posição da linha d'água, facilmente identificável em imagem de alta resolução, conforme o nível de maré no instante do imageamento. Quanto aos limites internos da orla, foi considerada a distribuição espacial das formas de relevo, bem como o tipo de ocupação. Nos setores urbanizados com falésias sedimentares, foi contabilizada a largura da faixa praial, mais a distância de $50 \mathrm{~m}$ medida a partir da borda superior das falésias em direção ao interior. Nos trechos com áreas de inundação e uso extrativista, recorreu-se ao limite interno da planície, incluindo toda a extensão da mesma. Desse modo, a orla do Maraú configura-se como um polígono de geometria irregular, apresentando dimensões que variam de $70 \mathrm{~m}$, nos trechos mais estreitos, a $2.000 \mathrm{~m}$, nas partes mais largas, e extensão de $5 \mathrm{~km}$ (Figura 2).

Figura 2 - Compartimentação morfológica do noroeste da ilha de Mosqueiro em



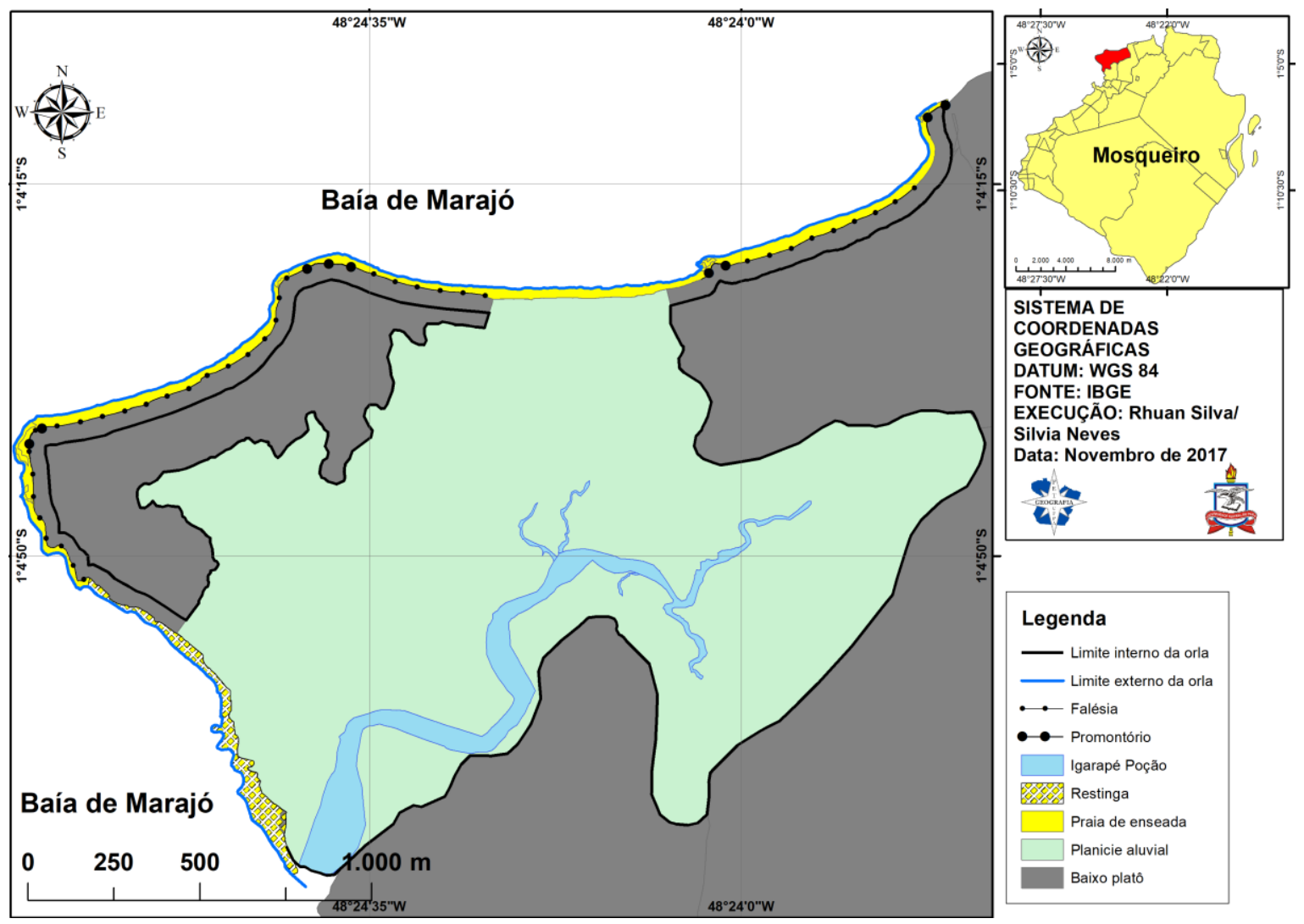


Fonte: Neves (2017).

Análise dos indicadores de dinâmica costeira da orla do Maraú, ilha de Mosqueiro, Belém, Pará.

A análise da dinâmica costeira desta orla baseou-se na identificação, na localização (distribuição espacial) e na classificação de indicadores relacionados aos seguintes fatores: largura do arco praial, posição da linha de maré alta, largura da pós-praia e do estirâncio, presença/ausência de sistema barra-calha, granulometria da areia praial, presença/ausência de terracetes, falésias, promontórios, plataformas de abrasão e bancos de cascalho, altura de falésias e promontórios, tipo de vegetação, condição erodida/soterrada, construções destruídas/soterradas e presença/ausência de tipos de feições erosivas/acrecionais.

Para cada indicador, foram atribuídos índices ou parâmetros e porcentagens. Desse modo, alguns indicadores receberam índices morfométricos ligados à largura, altura, extensão e quantidade. Outros foram definidos por um valor de porcentagem relativo à extensão de recobrimento/ocorrência na orla considerada. $E$, quanto à granulometria da areia, utilizaram-se somente as nomenclaturas: fina, média ou grossa. A partir da atribuição de parâmetros e porcentagens, obteve-se um total de 95 indicadores, subdivididos em físicos, biológicos e antrópicos/antropogênicos, de erosão, de sedimentação e de estabilidade (Quadros 2, 3 e 4).

Quadro 2 - Indicadores de erosão adotados para a análise da orla do Maraú, noroeste da ilha de Mosqueiro (Belém, Pará). Os indicadores estão divididos em físicos, biológicos e antropogênicos. Parâmetros, porcentagens e pesos.

\begin{tabular}{|l|l|}
\hline INDICADORES DE EROSÃO (FISICOS) & PESO \\
\hline 1. Largura do arco praial < $20 \mathrm{~m}$ & 3 \\
\hline 2. Largura do arco praial de 21 a $50 \mathrm{~m}$ & 2 \\
\hline 3. Largura do arco praial de 51 a $100 \mathrm{~m}$ & 1 \\
\hline 4. Posição da LMA em relação à base da duna ou da falésia < 1 m & 3 \\
\hline 5. Posição da LMA em relação à base da duna ou da falésia 1 a 2 m & 2 \\
\hline 6. Posição da LMA em relação à base da duna ou da falésia 3 m & 1 \\
\hline 7. Ausência de superfície de pós-praia/berma praial ou < 1m & 3 \\
\hline 8. Largura da superfície de pós-praia/berma praial 1 a 2 m & 2 \\
\hline 9. Largura da superfície de pós-praia/berma praial 3 m & 1 \\
\hline 10. Ausência de sistema barra/calha & 3 \\
\hline 11. Presença de 1 ou 2 sistemas barra/calha & 2 \\
\hline 12. Presença de 3 sistemas barra/calha & 1 \\
\hline 13. Largura da superfície de estirâncio < 20 m & 3 \\
\hline 14. Largura da superfície de estirâncio entre 21 a $50 \mathrm{~m}$ & 2 \\
\hline 15. Largura da superfície de estirâncio entre 51 e 100 m & 1 \\
\hline
\end{tabular}




\begin{tabular}{|c|c|}
\hline 16. Granulometria de areia média a grossa & 3 \\
\hline 17. Granulometria de areia fina a média & 2 \\
\hline 18. Granulometria de areia fina & 1 \\
\hline $\begin{array}{l}\text { 19. Presença de terracete ou escarpa lamosa ou arenosa próxima à } \\
\text { embocadura fluvial, nas superfícies de estirâncio e pós-praia ou na } \\
\text { base das dunas (acima de } 3 \text { unidades) }\end{array}$ & 3 \\
\hline $\begin{array}{l}\text { 20. Presença de terracete ou escarpa lamosa ou arenosa próxima à } \\
\text { embocadura fluvial, nas superfícies de estirâncio e pós-praia ou na } \\
\text { base das dunas ( } 2 \text { unidades) }\end{array}$ & 2 \\
\hline $\begin{array}{l}\text { 21. Presença de terracete ou escarpa lamosa ou arenosa próxima à } \\
\text { embocadura fluvial, nas superfícies de estirâncio e pós-praia ou na } \\
\text { base das dunas ( } 1 \text { unidade) }\end{array}$ & 1 \\
\hline $\begin{array}{l}\text { 22. Presença de falésias ativas e promontórios além de } 50 \% \text { da } \\
\text { extensão da orla ou do setor de orla }\end{array}$ & 3 \\
\hline $\begin{array}{l}\text { 23. Presença de falésias ativas e promontórios entre } 25 \% \text { e } 50 \% \\
\text { da extensão da orla ou do setor de orla }\end{array}$ & 2 \\
\hline $\begin{array}{l}\text { 24. Presença de falésias ativas e promontórios em até } 25 \% \text { da } \\
\text { extensão da orla ou do setor de orla }\end{array}$ & 1 \\
\hline 25. Altura da falésia e do promontório $\geq 3 \mathrm{~m}$ & 3 \\
\hline 26. Altura da falésia e do promontório de 1 a $2 \mathrm{~m}$ & 2 \\
\hline 27. Altura da falésia e do promontório $<1 \mathrm{~m}$ & 1 \\
\hline $\begin{array}{l}\text { 28. Presença de plataforma de abrasão além de } 50 \text { \% da extensão } \\
\text { da orla ou do setor de orla }\end{array}$ & 3 \\
\hline $\begin{array}{l}\text { 29. Presença de plataforma de abrasão entre } 25 \% \text { e } 50 \% \text { da } \\
\text { extensão da orla ou do setor de orla }\end{array}$ & 2 \\
\hline $\begin{array}{l}\text { 30. Presença de plataforma de abrasão em até } 25 \% \text { da extensão } \\
\text { da orla ou do setor de orla }\end{array}$ & 1 \\
\hline $\begin{array}{l}\text { 31. Presença de banco de cascalho além de } 50 \% \text { da extensão da } \\
\text { orla ou do setor de orla }\end{array}$ & 3 \\
\hline $\begin{array}{l}\text { 32. Presença de banco de cascalho entre } 25 \% \text { e } 50 \% \text { da extensão } \\
\text { da orla ou do setor de orla }\end{array}$ & 2 \\
\hline $\begin{array}{l}\text { 33. Presença de banco de cascalho em até } 25 \% \text { da extensão da } \\
\text { orla ou do setor de orla }\end{array}$ & 1 \\
\hline $\begin{array}{l}\text { 34. Afloramento de rochas sedimentares subjacentes ao manguezal } \\
\text { ou de sedimentos lamosos subjacentes à praia (além de } 50 \% \text { da } \\
\text { extensão da orla ou do setor de orla) }\end{array}$ & 3 \\
\hline $\begin{array}{l}\text { 35. Afloramento de rochas sedimentares subjacentes ao manguezal } \\
\text { ou de sedimentos lamosos subjacentes à praia (entre } 25 \% \text { e } 50 \% \\
\text { da extensão da orla ou do setor de orla) }\end{array}$ & 2 \\
\hline $\begin{array}{l}\text { 36. Afloramento de rochas sedimentares subjacentes ao manguezal } \\
\text { ou de sedimentos lamosos subjacentes à praia (até } 25 \% \text { da } \\
\text { extensão da orla ou do setor de orla) }\end{array}$ & 1 \\
\hline $\begin{array}{l}\text { 37. Presença de filetes de escorrimento de água subsuperficial } \\
\text { sobre a praia e falésia (além de } 50 \% \text { da extensão da orla ou do } \\
\text { setor de orla) }\end{array}$ & 3 \\
\hline $\begin{array}{l}\text { 38. Presença de filetes de escorrimento de água subsuperficial } \\
\text { sobre a praia e falésia (entre } 25 \% \text { e } 50 \% \text { da extensão da orla ou } \\
\text { de setor de orla) }\end{array}$ & 2 \\
\hline $\begin{array}{l}\text { 39. Presença de filetes de escorrimento de água subsuperficial } \\
\text { sobre a praia e falésia (até } 25 \% \text { da extensão da orla ou do setor de } \\
\text { orla) }\end{array}$ & 1 \\
\hline
\end{tabular}


40. Marcas de deslizamento, desabamento e solapamento na falésia (além de $50 \%$ da extensão da orla ou do setor de orla) 41. Marcas de deslizamento, desabamento e solapamento na falésia (entre $25 \%$ e $50 \%$ da extensão da orla ou do setor de orla) 42. Marcas de deslizamento, desabamento e solapamento na falésia (até $25 \%$ da extensão da orla ou do setor de orla) INDICADORES DE EROSÃO (BIOLÓGICOS)

43. Faixa frontal de mangue, vegetação de restinga ou mata aluvial destruída pela erosão (acima de $50 \%$ da área ou do setor de orla) 44. Faixa frontal de mangue, vegetação de restinga ou mata aluvial destruída pela erosão (entre $25 \%$ e 50 \% da área ou do setor de orla)

45. Faixa frontal de mangue, vegetação de restinga ou mata aluvial destruída pela erosão (até $25 \%$ da área ou do setor de orla) 46. Presença de vegetação de terra firme no arco praial (acima de 3 $50 \%$ da praia)

47. Presença de vegetação de terra firme no arco praial (entre $25 \%$ e $50 \%$ da praia)

48. Presença de vegetação de terra firme no arco praial (até $25 \%$ da praia) INDICADORES DE EROSÃO (ANTROPOGÊNICOS) 49. Construção e via situada na margem superior da falésia ou da praia com mais de $50 \%$ de destruição por agentes físicos 50. Construção e via situada na margem superior da falésia ou da praia com $25 \%$ a $50 \%$ de destruição por agentes físicos 51. Construção e via situada na margem superior da falésia ou da praia com até $25 \%$ de destruição por agentes físicos 52. Tubulação de água ou de esgoto, situada na margem superior, média ou inferior da falésia ativa, em situação de destruição por agentes físicos (acima de 4 unidades)

53. Tubulação de água ou de esgoto, situada na margem superior, média ou inferior da falésia ativa, em situação de destruição por agentes físicos ( 3 a 4 unidades)

54. Tubulação de água ou de esgoto, situada na margem superior, média ou inferior da falésia ativa, em situação de destruição por agentes físicos (até 2 unidades)

55. Presença de muros de arrimo e outras construções na base das falésias ativas ou isolados na superfície de estirâncio (acima de 4 unidades)

56. Presença de muros de arrimo e outras construções na base das falésias ativas ou isolados na superfície de estirâncio ( 3 a 4 unidades)

57. Presença de muros de arrimo e outras construções na base das falésias ativas ou isolados na superfície de estirâncio (até 2 unidades)

58. Alicerces, sapatas, pilares e vigas expostos devido à remoção de areia praial por ação das ondas (acima de $50 \%$ da extensão da orla ou do setor de orla)

59. Alicerces, sapatas, pilares e vigas expostos devido à remoção de areia praial por ação das ondas (entre $25 \%$ e $50 \%$ da extensão da orla ou do setor de orla) 
60. Alicerces, sapatas, pilares e vigas expostos devido à remoção de areia praial por ação das ondas (até $25 \%$ da extensão da orla ou do setor de orla)

Fonte: Organização dos autores.

Quadro 3 - Indicadores de estabilidade adotados para a análise da orla do Maraú, noroeste da ilha de Mosqueiro (Belém, Pará). Os indicadores estão acompanhados de seus respectivos parâmetros.

\begin{tabular}{|l|l|}
\hline INDICADORES DE ESTABILIDADE & PESO \\
\hline 61. Largura do arco praial entre 100 e 150 m & - \\
\hline $\begin{array}{l}\text { 62. Posição da linha de maré alta entre } 4 \text { e } 5 \mathrm{~m} \text { em relação à base } \\
\text { da duna ou da falésia }\end{array}$ & - \\
\hline 63. Largura da superfície de pós-praia/berma praial 4 e $5 \mathrm{~m}$ & - \\
\hline 64. Largura da superfície de estirâncio entre 101 a $150 \mathrm{~m}$ & - \\
\hline $\begin{array}{l}\text { 65. Presença de vegetação arbórea, arbustiva ou herbácea, } \\
\text { antropogênica ou não, sobre pós-praia/berma, planície alagável ou } \\
\text { falésia, recobrindo, no mínimo } 50 \% \text { da extensão da orla ou setor de } \\
\text { orla }\end{array}$ & - \\
\hline
\end{tabular}

Fonte: Organização dos autores.

Quadro 4 - Indicadores de acumulação adotados para a análise da orla do Maraú, noroeste da ilha de Mosqueiro (Belém, Pará). Os indicadores estão divididos em físicos, biológicos e antropogênicos. Parâmetros, porcentagens e pesos.

\begin{tabular}{|l|l|}
\hline INDICADORES DE ACUMULAÇÃO ( FíSICOS) & PESO \\
\hline 66. Largura do arco praial $>250 \mathrm{~m}$ & 3 \\
\hline 67. Largura do arco praial de 201 a $250 \mathrm{~m}$ & 2 \\
\hline 68. Largura do arco praial 150 a $200 \mathrm{~m}$ & 1 \\
\hline 69. Posição da LMA em relação à base da duna ou da falésia > 8 m & 3 \\
\hline 70. Posição da LMA em relação à base da duna ou da falésia 7 e $8 \mathrm{~m}$ & 2 \\
\hline 71. Posição da LMA em relação à base da duna ou da falésia 5 e $6 \mathrm{~m}$ & 1 \\
\hline 72. Largura da superfície de pós-praia/berma praial >8 m & 3 \\
\hline 73. Largura da superfície de pós-praia/berma praial 7 e $8 \mathrm{~m}$ & 2 \\
\hline 74. Largura da superfície de pós-praia/berma praial 5 e 6 m & 1 \\
\hline 75. Presença de 6 ou mais sistemas barra/calha & 3 \\
\hline 76. Presença de 5 sistemas barra/calha & 2 \\
\hline 77. Presença de 4 sistemas barra/calha & 1 \\
\hline 78. Largura da superfície de estirâncio >250 m & 3 \\
\hline 79. Largura da superfície de estirâncio entre 201 e 250 m & 2 \\
\hline 80. Largura da superfície de estirâncio 150 a 200 m & 1 \\
\hline 81. Granulometria de areia fina & 3 \\
\hline 82. Granulometria de areia fina a média & 2 \\
\hline 83. Granulometria de areia média a grossa & 1 \\
\hline $\begin{array}{l}\text { 84. Presença de zona de retenção ou faixa de acreção arenosa ou } \\
\text { lamosa por influência de embocadura fluvial de baixa hierarquia }\end{array}$ & 3 \\
\hline
\end{tabular}


(ocupa acima de $50 \%$ da área considerada)

85. Presença de zona de retenção ou faixa de acreção arenosa ou lamosa por influência de embocadura fluvial de baixa hierarquia (ocupa entre $25 \%$ e $50 \%$ da área considerada)

86. Presença de zona de retenção ou faixa de acreção arenosa ou lamosa por influência de embocadura fluvial de baixa hierarquia (ocupa até $25 \%$ da área considerada)

INDICADORES DE ACUMULAÇÃO (BIOLÓGICOS)

87. Presença de vegetação de mangue sobre superfície de estirâncio e/ou banco lamoso no interior de estuários, canais de maré ou lagunas (acima de $50 \%$ da área)

88. Presença de vegetação de mangue sobre superfície de estirâncio e/ou banco lamoso no interior de estuários, canais de maré ou lagunas (entre $25 \%$ e $50 \%$ da área)

89. Presença de vegetação de mangue sobre superfície de estirâncio e/ou banco lamoso no interior de estuários, canais de maré ou lagunas (em até $25 \%$ da área)

INDICADORES DE ACUMULAÇÃO ( ANTROPOGÊNICOS)

90. Zona de retenção ou acreção arenosa ou lamosa por influência de construção perpendicular à linha de costa (acima de 50 \% da extensão da orla ou do setor de orla)

91. Zona de retenção ou acreção arenosa ou lamosa por influência de construção perpendicular à linha de costa (entre $25 \%$ e $50 \%$ da extensão da orla ou do setor de orla)

92. Zona de retenção ou acreção arenosa ou lamosa por influência de construção perpendicular à linha de costa (até $25 \%$ da extensão da orla ou do setor de orla)

93. Construções ou vias de circulação soterradas por areias dunares ou praiais ou por lama de manguezal (acima de $50 \%$ da extensão da orla ou do setor de orla)

94. Construções ou vias de circulação soterradas por areias dunares ou praiais ou por lama de manguezal (entre $25 \%$ e $50 \%$ da extensão da orla ou do setor de orla)

95. Construções ou vias de circulação soterradas por areias dunares ou praiais ou por lama de manguezal (até $25 \%$ da extensão da orla ou do setor de orla)

Fonte: Organização dos autores.

Os indicadores são evidências da ação erosiva ou acumulativa de agentes naturais e antrópicos/antropogênicos, correspondendo a "cicatrizes", "assinaturas" ou "testemunhos" das modificações em curso na orla costeira (MUEHE, 2001; SOUZA, 2009). Por sua vez, os indicadores de estabilidade representam uma situação intermediária entre erosão e acumulação, demonstrando a inexistência de alterações significativas. A escolha dos indicadores foi pautada em revisão bibliográfica e em inventários de campo. Logo, eles são condizentes com a referida área de estudo por estarem relacionados com suas características morfológicas, de vegetação e de ocupação. 
A adoção de parâmetros e porcentagens conduziu à aferição do grau do fenômeno dinâmico. Esta classificação foi determinada pelo tipo e pela quantidade de indicadores presentes (erosão, acumulação ou estabilidade), bem como pelo peso de cada um (pesos 1, 2 ou 3, respectivamente, graus baixo, médio ou alto). Assim, o grau foi definido pelo peso mais frequente. Ressalta-se que a atribuição de pesos foi feita somente para os indicadores de erosão e de acumulação.

Para facilitar o mapeamento da distribuição espacial, os indicadores foram identificados por números de 1 a 95. Isso permitiu a localização de 37 indicadores na orla do Maraú, sendo 25 de erosão (Figura 3).

Figura 3 - Distribuição espacial dos indicadores de dinâmica costeira na orla do Maraú.



Fonte: Neves (2017).

A distribuição espacial dos indicadores permite dividir a orla em quatro setores, que se diferenciam entre si por características morfométricas e morfográficas, pela cobertura vegetal, tipo de ocupação humana e grau de erosão e/ou acumulação e situação de estabilidade. A classificação do fenômeno dinâmico, em cada compartimento, foi definida pela quantidade de indicadores de cada tipo 
(erosão, acumulação, estabilidade), enquanto que o grau de erosão ou de acumulação foi gerado a partir do peso mais frequente.

O setor 1 da orla do Maraú localiza-se na parte norte. Apresenta uma largura média de $96 \mathrm{~m}$, extensão de $2 \mathrm{~km}$ e é o mais densamente urbanizado. A ocupação estende-se pela margem da falésia e/ou pela porção superior da praia. Por se tratar de um setor urbanizado, com praias e falésias sedimentares, os limites internos da orla são definidos pela largura de $50 \mathrm{~m}$, contados a partir da borda superior das escarpas e das praias, segundo os critérios de delimitação propostos por Muehe (2001). Foi localizado um total de 22 indicadores de erosão, com predomínio do peso 1 (54 \% dos indicadores), classificando-se como de baixa erosão. Desse modo, foi registrado um arco praial com larguras entre 51 e 100 m, a linha de maré alta posiciona-se a uma distância superior a $3 \mathrm{~m}$ em relação à base das falésias, as plataformas de abrasão e bancos de cascalho ocupam até $25 \%$ do setor de orla, árvores tombadas e construções destruídas não ultrapassam $25 \%$ da área considerada. Apesar da baixa erosão, é o setor mais vulnerável, que apresenta maiores prejuízos materiais devido à concentração de casas comerciais e residenciais.

O setor 2 situa-se na parte noroeste da orla, estendendo-se por 1,5 km, com largura média de 100 m. A ocupação é esparsa e as residências, quando próximas da falésia, possuem estruturas reforçadas para controle do desgaste pela erosão, demonstrando maior poder aquisitivo e investimento financeiro por parte dos proprietários. São classificados 12 indicadores, predominando os de peso 2 (50\%), atestando situação de erosão média. Apresenta as seguintes características: o arco praial possui largura de até $50 \mathrm{~m}$, a linha de maré alta situa-se a uma distância de até $3 \mathrm{~m}$ em relação à base da falésia, superfícies de pós-praia de até $3 \mathrm{~m}$ e estirâncios de até $50 \mathrm{~m}$ de largura, granulometria da areia entre média e grossa, presença de falésias ativas e promontórios além de $50 \%$ da extensão da orla com alturas acima de $3 \mathrm{~m}$, plataformas de abrasão e bancos de cascalho ocupam uma extensão entre $25 \%$ e 50\% da orla, presença de filetes de escorrimento de água subsuperficial sobre a praia e falésia (entre $25 \%$ e $50 \%$ da extensão da orla), marcas de deslizamento, desabamento e solapamento na falésia (entre $25 \%$ e $50 \%$ da extensão da orla), construção e via situada na margem superior da falésia com até $25 \%$ de destruição por agentes físicos (Figura 4). 
Figura 4 - Indicadores de baixa erosão do setor 1 da orla do Maraú (A e B): ocupação comercial e residencial do estirâncio superior e pós-praia, arco praial com larguras entre 51 e 100 m, plataformas de abrasão ocupam até $25 \%$ do setor de orla. Indicadores de média erosão do setor 2 ( $C$ e D): falésias ativas com marcas de deslizamento, desabamento e solapamento ou revestidas com estruturas de contenção em concreto e madeira, superfície de pós-praia com largura de até $3 \mathrm{~m} \mathrm{e}$ estirâncios com até $50 \mathrm{~m}$.
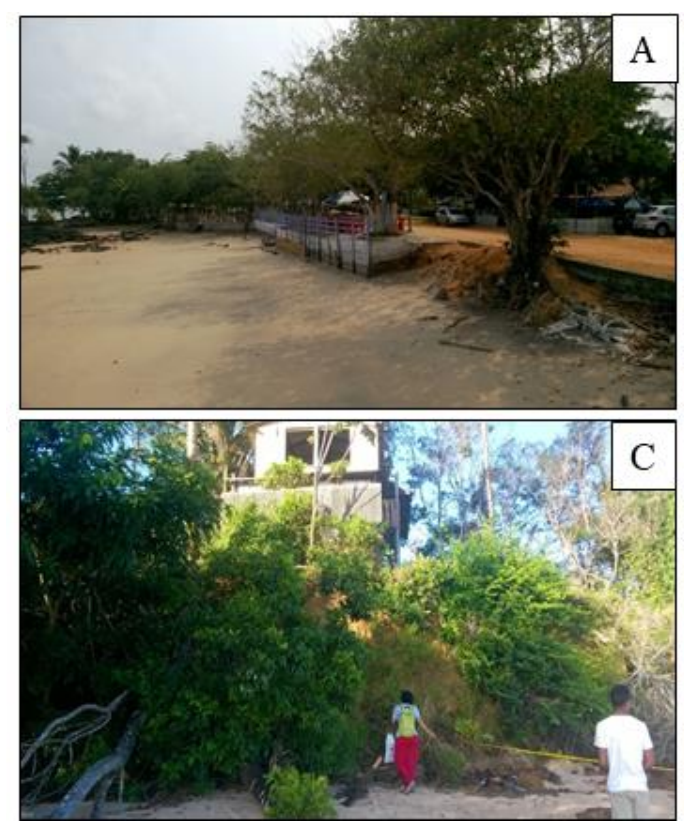

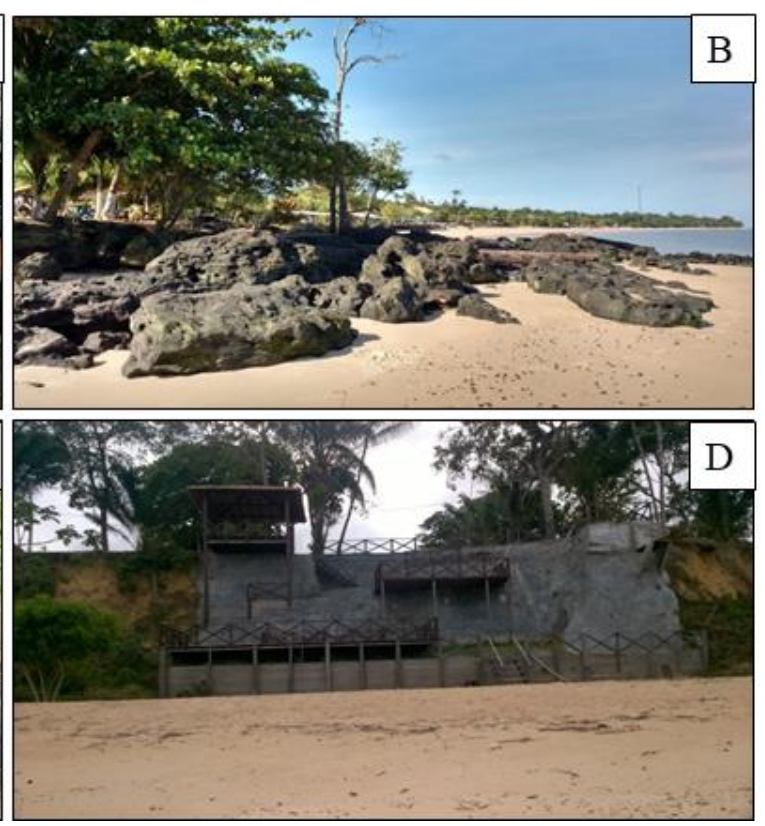

Fonte: Silvia Neves, maio e dezembro de 2016.

O setor 3 estende-se por 1,2 km no sudoeste. A feição morfológica mais importante é a restinga com largura entre 80 e 200 m, limitada ao sul pela embocadura do igarapé do Poção. É parcialmente recoberta por bosque que reveste o cordão arenoso acima do nível médio das marés, e por manchas de mangue nas áreas lamosas alagáveis. Não há ocupação urbana e o uso é extrativista. Foram localizados 10 indicadores de dinâmica costeira, dos quais 7 são de baixa acumulação com destaque para: largura do arco praial além de $100 \mathrm{~m}$, pós-praias com até $6 \mathrm{~m}$ de largura e estirâncios entre 50 e 100 m, granulometria fina a média e vegetação de mangue recobrindo até 25 \% da área, presença de vegetação arbórea, arbustiva e herbácea protegendo a faixa arenosa frontal (Figura 5).

Por fim, no setor 4, que ocupa toda a parte centro-sul da área de estudo, numa extensão entre 2 e $2,5 \mathrm{~km}$, há somente indicador de estabilidade, onde se registra a presença de vegetação arbórea recobrindo, no mínimo, 50 \% da extensão 
do setor de orla. Corresponde à área abrangida pela planície alagável revestida por cobertura florestal em bom estado de conservação e uso extrativista (Figura 6).

Figura 5 - Indicadores de baixa acumulação do setor 3 da orla do Maraú. Foto A: largura do arco praial além de $100 \mathrm{~m}$, pós-praias com até $6 \mathrm{~m}$ de largura e estirâncios entre 50 e 100 m, areias finas a médias. Ao fundo, vegetação de restinga; Foto B: indivíduo arbustivo em zona de pós-praia. Ao fundo, vegetação arbórea que recobre faixa arenosa acima do nível médio das marés.
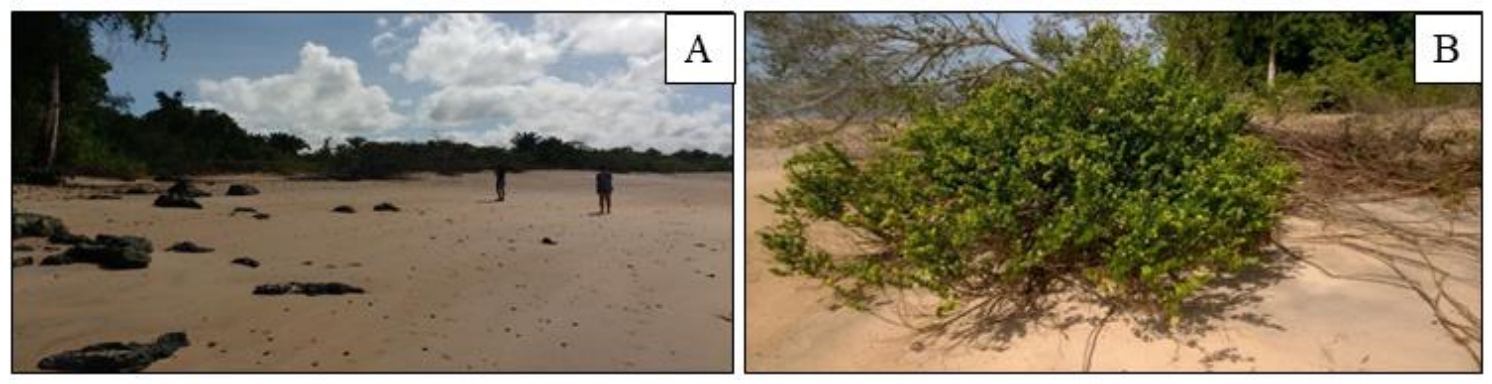

Fonte: Silvia Neves, dezembro de 2016.

Figura 6 - Classificação dos setores da orla do Maraú de acordo com o grau de dinâmica costeira.

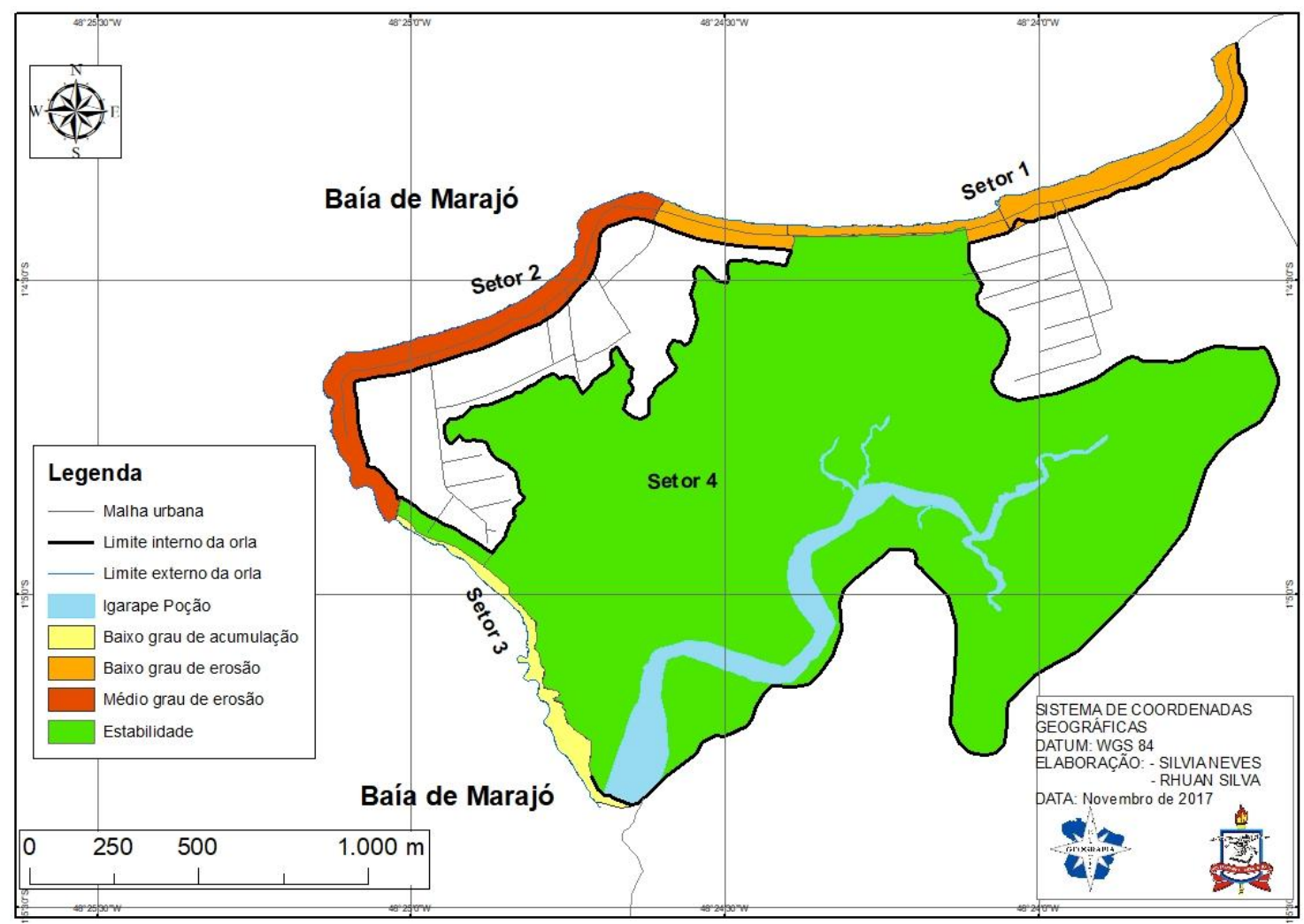

Fonte: Neves (2017). 
A análise da distribuição espacial dos indicadores de dinâmica costeira demonstra o predomínio da erosão, nos setores 1 e 2, mas com distintas frequências de pesos. Neste cenário erosivo, houve maior frequência de indicadores de baixa a média erosão. Nos setores 3 e 4, os registros foram de baixa acumulação e estabilidade, sugerindo uma relação entre esses fenômenos, como resultado da proximidade entre as duas áreas e das peculiaridades morfológicas, representadas pela presença da restinga e da planície aluvial.

A erosão é predominante, em grau baixo e médio, nos setores expostos às ondas da baía de Marajó. A acumulação e a estabilidade ocorrem em áreas protegidas em relação às ondas frontais ou em zonas internas alcançadas somente pelas marés. Nestas últimas há baixa densidade ocupacional, uso extrativista e bom estado de conservação do meio biofísico.

\section{Considerações Finais}

A análise da distribuição espacial dos indicadores de dinâmica costeira demonstra o predomínio da erosão, nos setores 1 e 2 , mas com distintas frequências de pesos. Neste cenário erosivo, houve maior frequência de indicadores de baixa a média erosão. Nos setores 3 e 4 , os registros foram de baixa acumulação e estabilidade, sugerindo uma relação entre esses fenômenos, como resultado da proximidade entre as duas áreas e das peculiaridades morfológicas, representadas pela presença da restinga e da planície aluvial.

A erosão é predominante, em grau baixo e médio, nos setores expostos às ondas da baía de Marajó. A acumulação e a estabilidade ocorrem em áreas protegidas em relação às ondas frontais ou em zonas internas alcançadas somente pelas marés. Nestas últimas há baixa densidade ocupacional, uso extrativista e bom estado de conservação do meio biofísico.

\section{REFERÊNCIAS}

BRASIL. Ministério do Meio Ambiente. Ministério do Planejamento, Orçamento e Gestão. Projeto Orla: Subsídios para um projeto de gestão. Brasília, DF: MMA, MP, 2004. 101 p. BRASIL. Ministério da Defesa. Marinha do Brasil. Tábua das Marés. Ilha de Mosqueiro (Estado do Pará)-2018. Disponível em https://www.marinha.mil.br/chm/sites/www.marinha.mil.br.chm/files/dados de mare/ilha do mosqueiro 2018.pdf. Acesso em 12 mar.2018.

CHRISTOFOLETTI, A. Geomorfologia. São Paulo: Edgard Blücher/EDUSP, 1980. 188 p. 
EL-ROBRINI, M. H. S. Variabilidade morfológica e sedimentar de praias estuarinas, ilha de Mosqueiro. 2001. 85 p. Dissertação (Mestrado em Geologia) - Universidade Federal do Pará, Belém.

GRUBER, N. L. S; BARBOZA, E. G; NICOLODI, J. L. Geografia dos sistemas costeiros e oceanográficos: subsídios para gestão integrada da zona costeira. Gravel, n. 1, p. 81- 89, 2003.

IGREJA, H. L. S.; BORGES, M. S.; ALVES, R. J.; COSTA JÚNIOR, P. S. C.; COSTA, J. B. S. Estudos neotectônicos nas ilhas de Outeiro e Mosqueiro, NE do Estado do Pará. In:

CONGRESSO BRASILEIRO DE GEOLOGIA, 36., 1990, Natal. Anais... Natal: SBG, 1990. v. 5, p. 2110-2123.

MUEHE, D. Critérios morfodinâmicos para o estabelecimento de limites da orla costeira para fins de gerenciamento. Revista Brasileira de Geomorfologia, v. 2, n. 1, p. 35-43, 2001. NEVES, S. C. R. Indicadores de dinâmica costeira na orla do Maraú, porção ocidental da ilha de Mosqueiro - Belém-Pará. 2017. 62 p. Monografia (Graduação em Geografia) Universidade Federal do Pará, Belém.

PINHEIRO, R. V. L. Estudo hidrodinâmico e sedimentológico do estuário Guajará Belém(PA). 1987. 164 p. Dissertação (Mestrado em Geologia) - Universidade Federal do Pará, Belém.

ROSS, J. L. S. O registro cartográfico dos fatos geomórficos e a questão da taxonomia do relevo. Revista do Departamento de Geografia, v. 6, p. 17-29, 1992.

ROSSETTI, D. F. Late Cenozoic sedimentary evolution in northeastern Pará, Brazil, within the context of sea level changes. Journal of South American Earth Sciences, n. 14, p. 7789, 2001.

SOUZA, C. R. G. A erosão nas praias do Estado de São Paulo: causas, consequências, indicadores de monitoramento e risco. In: BONONI, V. L. R.; SANTOS, N. A. Jr. (Org.).

Memórias do Conselho Científico da Secretaria do Meio Ambiente: a síntese de um ano de conhecimento acumulado. São Paulo: Instituto de Botânica, Secretaria do Meio Ambiente do Estado de São Paulo, 2009. p. 48-69.

VIANA, I. G. S. Estrutura e fisiologia da paisagem da praia do Areião, Ilha de Mosqueiro (Belém-PA). 2013. 87 p. Dissertação (Mestrado em Geografia) - Universidade Federal do Pará, Belém.

\section{NOTAS DE AUTOR}

\section{CONTRIBUIÇÃO DE AUTORIA}

Silvia Caroline Ribeiro Neves - Concepção. Coleta de dados, Análise de dados, Participação ativa da discussão dos resultados, Elaboração do manuscrito, revisão e aprovação da versão final do trabalho. Carmena Ferreira de França - Concepção. Coleta de dados, Análise de dados, Participação ativa da discussão dos resultados, Elaboração do manuscrito, revisão e aprovação da versão final do trabalho.

Rhuan Rodrigo Pereira e Silva - Concepção. Coleta de dados, Análise de dados, Participação ativa da discussão dos resultados, Elaboração do manuscrito, revisão e aprovação da versão final do trabalho.

\section{FINANCIAMENTO}

Bolsa do Programa de Educação Tutorial (PET/FNDE/MEC).

\section{CONSENTIMENTO DE USO DE IMAGEM}

Não se aplica.

APROVAÇÃO DE COMITÊ DE ÉTICA EM PESQUISA

Não se aplica.

\section{CONFLITO DE INTERESSES}

Não se aplica.

\section{LICENÇA DE USO}

Este artigo está licenciado sob a Licença Creative Commons CC-BY. Com essa licença você pode compartilhar, adaptar, criar para qualquer fim, desde que atribua a autoria da obra.

\section{HISTÓRICO}

Recebido em: 29-08-2018

Aprovado em: 08-05-2019 